\title{
Private rest homes in the care of the elderly
}

\author{
KEITH ANDREWS
}

\begin{abstract}
Sixteen private rest homes were visited to assess their facilities and the types of disability of the residents. Apart from one home, which was a hotel for the elderly, all the homes provided care for physically and mentally frail elderly people over the long term. Although care was good the trends in the use of the homes are worrying, and stricter regulations are required to ensure appropriate levels of care. Greater support is also required from district nursing services.
\end{abstract}

\section{Introduction}

In Britain the elderly are a high priority for health and social services yet other countries have taken a greater political lead in providing them with suitable long term accommodation. ${ }^{1-3}$

Social frailty is blamed for the "blocking" of hospital beds ${ }^{4}$ and unnecessary admission to hospital, ${ }^{6}$ though length of stay is usually related to morbidity rather than to social or administrative factors. ${ }^{7}$ Nevertheless, disorders such as dementia, poor mobility, and functional dependency are the main barriers to independent living. ${ }^{8} 9$ Intensive hospital at home schemes may prevent some acute admissions to hospital, ${ }^{10} 11$ but long term supervision often requires institutional care. Social service residential homes are increasingly dealing with heavily dependent clients, ${ }^{12}$ though few have staff with any nursing qualifications, ${ }^{13}$ while many patients in long stay wards are suitable for social service homes. ${ }^{14}$

There has been a rapid increase in the number of private rest homes in the past few years. Between 1976 and 1979 their number of places increased by $18.8 \%$ compared with only $1 \%$ in those in social service residences, ${ }^{15}$ and most areas report an even more rapid increase in the past three years. One factor in this growth has been the increased awareness of DHSS funding for private rest home care if a place in a social service home is unavailable. ${ }^{16}$ Press and television reports have expressed concern about the number of staff in rest homes while describing aspects of neglect and implying that there is pressure to remove an old person from rest homes when they deteriorate. Little, however, is known about rest homes in general and this paper investigates the policy and client characteristics of a group of rest homes in one area.

\section{Method}

I visited 16 private rest homes, excluding charitable or religious institutions and nursing homes, in the immediate catchment area of a district general hospital to assess the policy of the home and the type of care provided. I recorded information about each resident, and each visit lasted about one hour, taking the form of a structured interview followed by an informal discussion.

\section{Results}

Of the 16 homes visited, one accepted only mobile and mentally alert individuals. This home was registered for 45 residents, of whom

University Hospital of South Manchester, Manchester M20 8LR KEITH ANDREWS, MD, MRCP, consultant geriatrician
10 were funded by social security payments. The proprietor regarded the home as a residential hotel and felt that confused or dependent residents would affect the quality of life of the others and would therefore seek a place in another rest home if a client deteriorated. Since this home differed from all the others in the area in both policy and the characteristics of its residents I have excluded it from the analysis. The other 15 homes provided continuing care for frail elderly individuals irrespective of deterioration.

Only $83 \%$ of the 213 registered places in the homes were occupied. Some $61(29 \%)$ of the places were in single rooms. Two thirds of the homes had 15 or fewer places while only two had more than 20 residents. All but one of the homes had some bedrooms on the first floor and all but two of these had either a lift or a stair lift.

\section{$\cos \mathrm{T}$}

The average cost of a single room was $£ 131$ a week (range $£ 75-170$ ) and $£ 120$ a week for a shared room (range $£ 65-155$ ). In all the homes this cost included meals and laundry, and in half it also included hairdressing.

\section{STAFFING}

The attendant:resident ratio at any one time was 0.25 during the day and 0.13 at night for each place available. Since many proprietors employed staff according to occupancy the equivalent figures for occupied places was $0 \cdot 3$ during the day and $0 \cdot 16$ at night. The number of staff does not include those, usually the proprietors, who were available if needed but were not officially on duty.

\section{DISABILITIES ACCEPTED}

Nearly all of the homes accepted physically or mentally impaired individuals provided that professional nursing care was not needed. Only one home, the cheapest, was reluctant to accept residents who were incontinent or confused, or had difficulties in dressing, though it was prepared to continue care if these features developed during the stay. Two homes were reluctant to accept individuals with problems of balance and six were usually unable to accept patients in wheelchairs because of lack of space.

\section{ACTIVITIES}

Only two homes had no apparent organised activities. Eight had formally organised handicraft sessions, seven arranged outings, six employed entertainers regularly, and one had a fully stocked bar.

\section{RESIDENTS}

Most $\left(84^{\circ}{ }_{0}\right)$ of the residents were women. The mean age was 83 for women and 78 for men, while the average length of stay was 24 months and 10 months respectively.

About half of the residents had been admitted from hospital, $41 \%$ from home, and $8 \%$ had been transferred from another rest home.

Only $29^{\circ} \%$ of residents were neither incontinent nor confused; $12 \%$ were incontinent but not confused, $28 \%$ confused but not incontinent, and $33^{\circ}$ incontinent and confused.

The commonest physical conditions present on admission were: general frailty $(13 \%)$, falls $(12 \%)$, stroke $(11 \%)$, arthritis $(11 \%)$, blindness $(9 \%)$, fractures $(6 \%)$, carcinoma $(5 \%)$, and personality disorders $\left(5^{\circ}{ }_{0}\right)$. 


\section{SUBJECTIVE IMPRESSION}

The homes varied widely from basic provision in adapted old houses to purpose designed modernised buildings. Nevertheless, all the homes were clean and warm. The overriding impression was one of homeliness, probably because of the small number of residents in a normal house environment. Most of the homes gave an impression of general activity with a lot of staff-resident contact, though in several homes all the residents were asleep in centrifugally placed chairs.

The proprietors often worked long hours, and although available cost value; secondly, the resident was transferred as soon as a place in a social service home was available, producing insecurity for both client and the owner of the rest home.

One problem with social security funding was that local DHSS offices set their own ceiling for payments. One local office set a limit of $£ 100$, effectively blocking admission to nearly all of the rest homes. Although the social service department had to confirm that a place in one of their homes was not available, there seemed to be no need to show that the client would have been accepted for residential care. Social security provision was therefore on the basis of demand rather than of need.

TABLE I-Characteristics of private rest homes

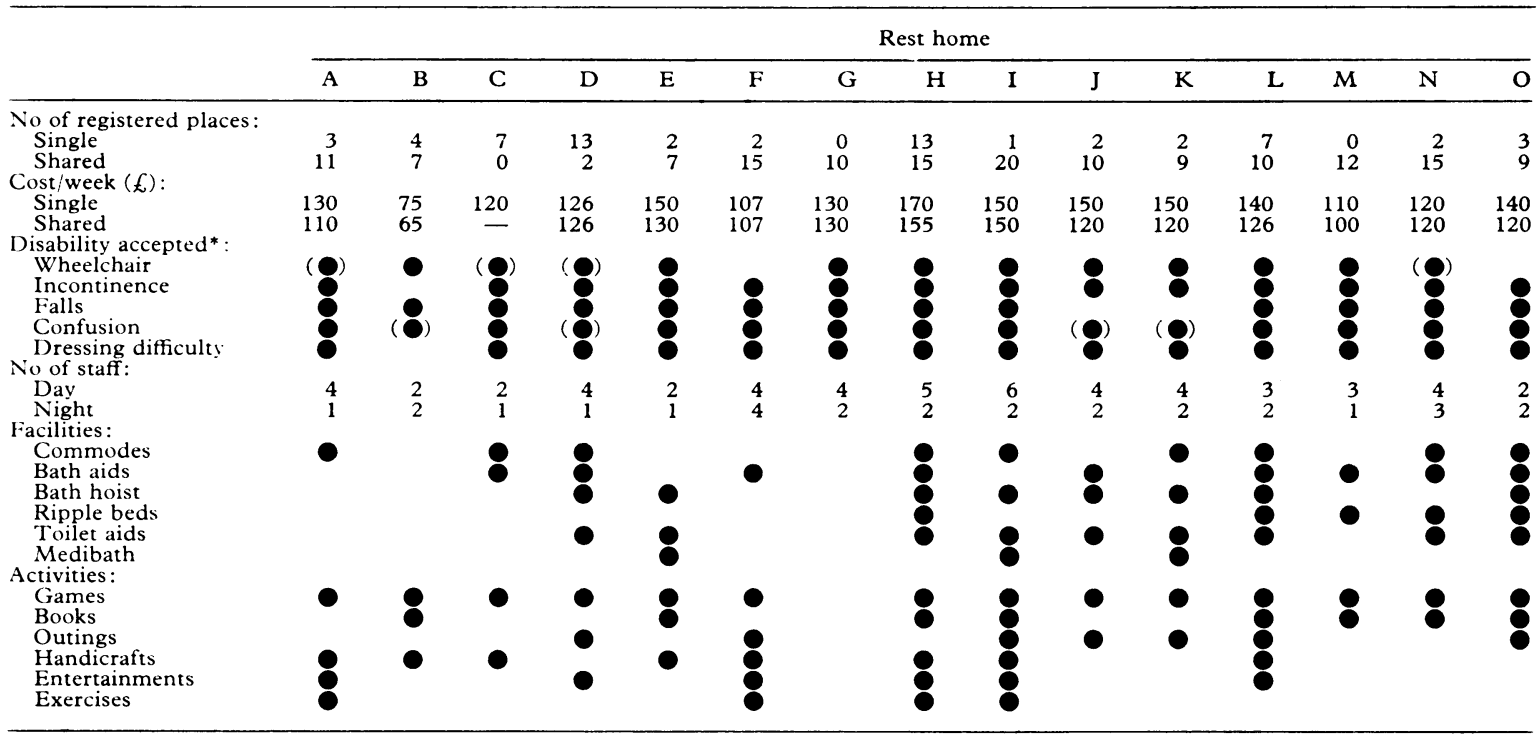

$*(\mathbf{O})=$ limited.

TABLE II-Characteristics of residents in the private rest homes. Results are numbers of residents

\begin{tabular}{|c|c|c|c|c|c|c|c|c|c|c|c|c|c|c|c|}
\hline & \multicolumn{15}{|c|}{ Rest home } \\
\hline & A & B & $\mathrm{C}$ & $\mathrm{D}$ & $\mathrm{E}$ & $\mathrm{F}$ & G & $\mathbf{H}$ & I & J & $\mathbf{K}$ & $\mathrm{L}$ & $\mathrm{M}$ & $\mathbf{N}$ & $\mathrm{O}$ \\
\hline \multicolumn{16}{|l|}{ Residents: } \\
\hline Men & 1 & $\begin{array}{l}0 \\
3\end{array}$ & 2 & 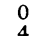 & $\begin{array}{l}0 \\
8\end{array}$ & 0 & 4 & 4 & 7 & 0 & 0 & 4 & 3 & 1 & 2 \\
\hline Social security funded & 13 & $\begin{array}{l}3 \\
2\end{array}$ & $\begin{array}{l}5 \\
3\end{array}$ & $\begin{array}{l}4 \\
2\end{array}$ & $\begin{array}{l}8 \\
4\end{array}$ & $\begin{array}{r}15 \\
2\end{array}$ & 4 & $\begin{array}{r}20 \\
3\end{array}$ & $\begin{array}{l}7 \\
7\end{array}$ & $\begin{array}{r}12 \\
4\end{array}$ & 11 & 12 & $\begin{array}{l}9 \\
4\end{array}$ & $\begin{array}{r}15 \\
4\end{array}$ & $\begin{array}{r}10 \\
0\end{array}$ \\
\hline Incontinent & 5 & 0 & 3 & 1 & 3 & 8 & 4 & 16 & 6 & $\begin{array}{l}4 \\
3\end{array}$ & 1 & $\begin{array}{l}1 \\
9\end{array}$ & 7 & 3 & 6 \\
\hline Confused & 7 & 0 & 2 & 3 & 5 & 12 & 3 & 17 & 8 & 8 & 8 & 6 & 12 & 8 & 6 \\
\hline \multicolumn{16}{|l|}{ Admitted from: } \\
\hline $\begin{array}{l}\text { Home } \\
\text { Geriatric unit }\end{array}$ & 4 & 0 & $\begin{array}{l}3 \\
1\end{array}$ & $\frac{1}{3}$ & $\begin{array}{l}0 \\
3\end{array}$ & 4 & $\begin{array}{l}4 \\
1\end{array}$ & 8 & $\begin{array}{l}5 \\
4\end{array}$ & $\frac{3}{5}$ & $\begin{array}{l}1 \\
9\end{array}$ & $\begin{array}{r}14 \\
0\end{array}$ & $\begin{array}{l}6 \\
3\end{array}$ & $\begin{array}{l}5 \\
4\end{array}$ & $\begin{array}{l}6 \\
4\end{array}$ \\
\hline Psychiatric unit* & 0 & 0 & 0 & 0 & 2 & 2 & 2 & 3 & 1 & 1 & 0 & 0 & 1 & 3 & 0 \\
\hline Other hospital & 3 & 0 & 3 & 0 & 3 & 1 & 0 & 1 & 2 & 2 & 1 & 1 & 0 & 4 & 2 \\
\hline Rest home & 0 & 0 & 0 & 0 & 0 & 1 & 1 & 6 & 2 & 1 & 0 & i & 2 & 0 & 0 \\
\hline
\end{tabular}

*Includes psychogeriatric units.

often did not include themselves in the staffing levels. They were obviously cost conscious and employed temporary staff as required and part time staff to cover peak times of the day.

A common problem was the reluctance of the district nursing services to provide aids and appliances which would normally have been available had the patient been cared for at home. Most of the staff seemed to understand common problems such as incontinence or confusion and coped with them extremely well. In some homes, however, basic training would have improved the care given to the residents.

Although private rest homes are run for a profit it was obvious that some of the homes were making so little as to raise the question of the viability of the business. The financial problems were made worse by delay in DHSS payments. One quarter of the residents were funded by social security arrangements and this proportion would probably have been higher except that one social service area contracted places in rest homes until a place was available in a social service home and therefore social security funding was not applicable. This had two consequences: the first was that the social service department would pay the rest home only $£ 90$ per week, below the
The rest homes are willing to accept vulnerable elderly people but selection of the more independent individuals was beginning to take place.

\section{Discussion}

The numbers of private rest homes are increasing, and in view of the rapid expansion of the very old population they are likely to have a potential market for some time to come. Present DHSS regulations allow payment for care in a private rest home provided that the client cannot pay and there is no place available in a social service residential home.

If private rest homes are to be of practical help in the care of the elderly then they will need to cope with dependent elderly people. Only one home was primarily for relatively independent individuals who would benefit from hotel accommodation. The other homes were coping with physical and 
mental handicap and were prepared to continue doing so. So far as I could see none of the residents required specialist nursing skills but they were receiving care which could be provided by a family. In view of the large amount of disability, staff training in management of the elderly is necessary. It is also disturbing to find that the district nursing services were taking a negative attitude to supporting individuals who were theoretically entitled to services. The high incidence of incontinence especially is an indication for closer liaison between the homes and the health services.

It is difficult to judge from a single visit what the quality of life was like in the homes. There seemed to be a reasonable staff:client ratio and the homely environment catering for small groups was attractive. Though these impressions are all subjective, there was no evidence of neglect and this is supported by private discussions with residents and from feedback from other visitors to the homes.

These findings, of course, apply only to the rest homes I saw during the study, and undoubtedly there is real concern about the standard of care in some rest homes. Although there are strict building and fire regulations, the social service departments have few powers to enforce good care and can intervene only in cases of serious neglect. The proprietors of the rest homes were also concerned that homes with poor standards reflected on private rest homes in general and all seemed to want stricter regulations to protect their own interests.

There are problems with the concept of rest homes, especially when paid for from public funds. Their success may, for political expediency, lead to a decrease in the provision of social service residential homes. Unfortunately the indications are that the private homes are beginning to select residents on their ability rather than their disability. This is encouraged by the willingness of the DHSS to fund private care irrespective of the need of the individual. It would seem logical that a condition for payment from public funds should be that an individual has first met the criteria for admission to a social service home.

Experience of medical screening before admission to social service homes has shown that as many as one third of clients are more suitable for alternative forms of accommodation and this figure would almost certainly be higher for private rest homes. ${ }^{17}$ Would public funds be more appropriately spent on increasing community support for a larger number of people than indiscriminate funding of rest home places? This policy would require selection of those admitted to rest homes. The people most likely to benefit would be those who require very frequent supervision especially when living alone. Although many would be mentally frail, others with multiple falls, blindness, stroke, severe arthritis, or self neglect would be suitable.

Unlike social service departments, private rest homes are not limited to specific catchment areas and therefore it is easier to move an elderly person to a home near to their family. This does, however, raise the problem of whose responsibility it is to find alternative accommodation should admission to the home be unsuccessful, especially if long term residential care is required. Thus no fewer than $8 \%$ of the residents in homes had been transferred from other rest homes. This might be to the client's advantage, and is a facility less easily available from the statutory institutions, but it may also indicate that problem clients are shunted from one place to another.

One major concern of health and social service professionals was what would happen if a home had to close down. In one area over 20 places had had to be found in social service homes and geriatric units on one weekend because of the unexpected closure of a private rest home. Because of this possibility there is a danger that social service departments have a vested interest in keeping even unsuitable rest homes open and hence it would seem advisable that assessment for continuing registration should be carried out by an independent body.

In general I was more impressed than I expected to be by the amount and quality of care provided in the private homes in this area. If the homes continue to function as at present then they have much to offer. The problems are more a danger of misuse of these facilities, especially the provision of funding by DHSS. To avoid this I suggest that greater control over the rest homes for the quality of care and type of individual accepted is required. If the health services are to benefit from the rest homes they should be prepared to give advice, training, and the necessary back up of district nursing services.

I am grateful to the proprietors and staff of the rest homes for their help with this study and for allowing me to view their premises.

\section{References}

1 Smith T. Denmark: the elderly living in style. $B r$ Med $\mathcal{F} 1983 ; 287$ : 1053-5.

2 Godber C. A happier old age in Denmark. Br Med f 1982;284:1729-30.

${ }^{3}$ Smith T. Care of the elderly in the Netherlands. Br Med $\mathcal{F} 1984 ; 288$ : 127-9.

${ }^{4}$ Rubin SG, Davies GH. Bed blocking by elderly patients in general hospital wards. Age Ageing 1975;4:142-7.

${ }^{5}$ Leonard JC. Can geriatrics survive. Br Med f 1976;i:1335-6.

${ }^{6}$ Currie CT, Smith RG, Williamson J. Medical nursing needs of elderly patients admitted to acute medical beds. Age Ageing 1979;8:149-51.

${ }^{7}$ Seymour DW, Pringle R. Elderly patients in a general surgical unit: do they block beds? Br Med f 1982;284:1921-3.

${ }^{8}$ Hodkinson HM, Hodkinson I. Death and discharges from a geriatric department. Age Ageing 1980;9:220-8.

${ }^{9}$ Isaacs B. Prognostic factors in elderly patients in a geriatric institution. Gerontol Clin 1965; 7:202-15.

10 Mowat IG, Morgan RTT. Peterborough hospital at home scheme. $\mathrm{Br}$ Med f $1982 ; 284: 641-3$.

11 Cang SA, Clark F. Home care of the sick-an emerging general analysis based on schemes in France. Community Health 1978;9:167-72.

12 Clarke M, Hughes AO, Dodd KJ, et al. The elderly in residential care: pattern of disability. Health Trends 1979;11:17-20.

${ }^{13}$ Department of Health and Social Security. Residential care for the elderly in London. London: HMSO, 1979.

14 Dodd K, Clarke M, Palmer RL. Misplacement of the elderly in hospitals and residential homes: a survey and follow up. Health Trends 1980; 12:74-6.

15 Donaldson LJ, Clarke M, Palmer RL. Institutional care of the elderly: the impact and implications of the ageing population. Health Trends 1983;15:58-61.

${ }^{16}$ Regulation 9, Supplementary Benefit Requirements, Resource and Single Payment Amendment Regulation. Circular F/143. London: DHSS.

17 Brocklehurst JC, Carty MH, Leeming JT, Robinson JM. Medical screening of old people accepted for residential care. Lancet 1978;ii: 141-3.

(Accepted 9 March 1984)

Drugs such as phenelzine are said to act by inhibiting monoamine oxidases in the body. Is it possible, either by diet or drugs, to achieve the opposite effect-that is, to enhance or increase the activity of monoamine oxidases?

Monoamine oxidase is a group of related enzymes located in the mitochondria and widely distributed throughout the body. Its activity is influenced by many factors-for example, there is a genetically determined interindividual variation and activity is higher in women than in men. ${ }^{1}$ Monoamine oxidase activity in the uterus increases in the second half of the menstrual period and can be increased by progesterone. ${ }^{2}$ Dopamine, a substrate, also increases monoamine oxidase activity in the uterus of the rat. ${ }^{3}$ I have not been able to find any evidence that other drugs can increase its activity. The concentrations of monoamine oxidase in most tissues are excessive-for example, in animal experiments $80^{\prime \prime}$ "inhibition by a monoamine oxidase inhibitor is necessary before amine disposition is altered. Thus increasing the activity of monoamine oxidase would be unlikely to have any measurable effect on amine concentrations. LINDA BEELEY, consultant clinical pharmacologist, Birmingham.

Murphy DL. Monoamine oxidase, monoamine uxidase inhibiting drugs, and human behaviour. Handbook of psychopharmacology 1978;14:59-82.

Mazumder RC, Glover V, Sandler M. Progesterone provokes a selective rise of monoamine oxidase A in the female genital tract. Biochem Pharmacol 1980;29: $1957-9$.

Collins GGS, Pryse-Davies J, Sandler M, Southgate J. Effect of pretreatment wat. Nature $1970 ; 226: 642-3$.
rath 